\title{
FRACTURE RESISTANCE OF ENDODONTICALLY TREATED TEETH OBTURATED WITH DIFFERENT ROOT CANAL SEALERS (IN VITRO STUDY)
}

\author{
Abeer Ahmed Saba* and Heba Ahmed ElAsfouri**
}

\begin{abstract}
Aim of the study: was to compare the in vitro effect of three different root canal sealers used with gutta-percha, on the fracture resistance of endodontically treated teeth.

Materials and Methods: Forty extracted human single-rooted mandibular premolars were used for the study. Teeth were decoronated to a standard root length of $14 \mathrm{~mm}$. MPro rotary files up to master rotary size $25 / 6 \%$ were used for preparing the root canals. Teeth were randomly divided into five groups ( $\mathrm{n}=8 \mathrm{each}$ ) based on the type of root canal sealers used and the obturation was completed using gutta-percha; Group I: AH Plus root canal sealer, Group II: Endoseal MTA sealer, Group III: Bioroot RCS sealer, Group IV: Control-1 (prepared- unfilled) and Group V: Control-2 (unprepared-unfilled). Each specimen was embedded in acrylic mold and subjected to fracture resistance test using a universal testing machine under compressive loading at a rate of $1.0 \mathrm{~mm} / \mathrm{min}$ until fracture. The force required to fracture each specimen was recorded and the data obtained were statistically analyzed (analysis of variance (ANOVA) and paired-t test) with level of significance set at $p \leq 0.05$.
\end{abstract}

Results: The unprepared-unfilled group showed the highest mean fracture resistance followed by AH Plus group, Bioroot RCS group, then the Endoseal MTA group. While the prepared-unfilled group showed the least mean fracture resistance. There was no statistically significant difference between all groups.

Conclusion: It could be concluded that Bioroot RCS and Endoseal MTA are able to reinforce the tooth against fracture as good as AH Plus.

Keywords: AH Plus, Endoseal MTA, Bioroot RCS, fracture resistance.

* Associate Professor of Endodontics, Faculty of Dentistry, Cairo University.

** Lecturer of Endodontics, Faculty of Dentistry, Cairo University. 


\section{INTRODUCTION}

Endodontically treated teeth are known to be more liable to fracture than vital teeth. This is mostly due to the removal of tooth structure during endodontic treatment, dehydration of dentin after mechanical preparation, and excessive pressure during obturation ${ }^{(1,2)}$. In addition, intracanal irrigants and medications may also play role in changing the physical and mechanical properties of dentin, increasing the possibility of fracture ${ }^{(3)}$.

For this reason, one of the goals of root canal filling is to reinforce the root to enhance the fracture resistance, thus using a root canal sealer that can strengthen the root would be beneficial ${ }^{(4,5)}$.

To reinforce the tooth, sealers must have enough cohesive strength to hold the obturation together as well as adhere to both dentin and core material. This hypothesis had led to the development of adhesive root canal sealers ${ }^{(6-8)}$.

Gutta-percha with the epoxy resin-based AH plus sealer, is considered the gold standard in current obturation systems. Conflicting results had been reported regarding using this combination on fracture resistance of endodontically treated teeth. Although some studies ${ }^{(9-12)}$ showed that this combination had significantly increased fracture resistance yet, others showed no significant influence ${ }^{(13-19)}$.

Mineral trioxide aggregate (MTA) has been widely used in endodontics due to its ability to induce tissue repair and to stimulate mineralization. To enhance their clinical performance, several modifications in the composition of MTA-based cements have led to the introduction of novel formulations in the market ${ }^{(20)}$.

Tricalcium silicate-based cements, commonly known as MTA-based cements, are hydrophilic which require water to set. They have good biocompatibility and apatite-forming ability ${ }^{(21,22)}$.
BioRoot RCS (Septodont, Saint-Maur-des Fosses, France) is a powder/liquid hydraulic tricalcium silicate-based cement marketed since February 2015 and recommended for single cone technique or cold lateral condensation root filling. The powder contains tricalcium silicate, povidone and zirconium oxide; while the liquid is an aqueous solution of calcium chloride and polycarboxylate (23). Studies showed that BioRoot RCS has lower toxicity than other conventional root canal sealers, may induce hard tissue deposition ${ }^{(24-26)}$, and has antimicrobial activity ${ }^{(26)}$.

The EndoSeal MTA (Maruchi, Wonju, Korea) is another calcium silicate-based sealer containing MTA, and has shown favorable biocompatibility, antimicrobial activity, and good sealing ability ${ }^{(28)}$. It is introduced in a premixed paste form with the characteristics of hardening at the moist canal environment.

To our knowledge, no studies have compared the effect of AH Plus sealer, BioRoot RCS and EndoSeal MTA, on the fracture resistance of roots filled with them in combination with gutta-percha, which was the aim this study.

The null hypothesis is that; there is no significant difference in fracture resistance between roots filled with either AH Plus, BioRoot RCS or EndoSeal MTA when used with gutta-percha.

\section{MATERIALS AND METHODS}

Ethical approval was obtained from the ethical committee (19/2/29) of Faculty of Dentistry, Cairo University.

\section{Sample selection}

Forty freshly extracted, single-canalled human mandibular premolars with comparable dimensions were selected and stored in distilled water until use. Teeth were examined for root cracks, abnormal curvatures, calcifications and internal or external resorption. 
Sample size calculation was done using $\mathrm{R}$ statistical package, version 3.3.1 (21-06-2016). Copyright (C) 2016, the R Foundation for Statistical Computing.* One-way analysis of variance power calculation for more than two groups was used to detect the proper sample size. Means and standard deviations were determined according to Guneser et al. $2016^{(29)}$ based on the fracture resistance of obturated roots. The results showed that, at a power of $90 \%$ and a two-sided significance level of 5\%; a total sample size of 40 single rooted teeth (equally allocated to five groups) will be adequate to reject the null hypothesis that the group means are equal; i.e. there is no difference between groups regarding fracture resistance.

All crowns were sectioned to obtain a standardized root length of $14 \mathrm{~mm}$ using a diamond saw under coolant. The working length was determined by subtracting $1 \mathrm{~mm}$ from the length of an inserted \#10 K-file (Dentsply Maillefer, Ballaigues, Switzerland) with its tip visualized at the apical foramen. All teeth were instrumented up to a master apical file size of 25/6\% with MPro rotary files using torque and speed-controlled electric motor (X Smart; Dentsply, Maillefer, Ballaigues, Switzerland) according to the manufacturer's instructions. A $3 \mathrm{~mL}$ of $5.25 \%$ Sodium hypochlorite solution $(\mathrm{NaOCl})$ was used between each file size. After instrumentation of the root canals, the smear layer was removed by rinsing the root canals with $5 \mathrm{~mL}$ of $5.25 \% \mathrm{NaOCl}$ and 5 $\mathrm{ml}$ of $17 \%$ EDTA solution (Merck, Darmstadt, Germany). The canals were finally flushed with $5 \mathrm{~mL}$ distilled water and dried with $25 / 6 \%$ paper points.

\section{Sample grouping}

Teeth were randomly divided into five equal groups $(n=8)$ according to the sealer used; Group I: AH Plus root canal sealer (Dentsply DeTrey, Kon- stanz, Germany), Group II: Endoseal MTA sealer (Maruchi, Wonju, South Korea), Group III: Bioroot RCS sealer (Septodont, Saint-Maurdes Fosses, France), Group IV: Control-1 (prepared- unfilled) and Group V: Control-2 (unprepared-unfilled).

In $\mathrm{AH}$ Plus and BioRoot RCS groups, the sealers were prepared according to manufacturer's instructions and introduced into the canal with size 25 Lentulospiral (Dentsply, Maillefer, Ballaigues, Switzerland) at 300 rotations/min to the working length until complete filling of the canal. In Endoseal MTA group, the sealer was injected into the root canal using intracanal tip supplied by the manufacturer, to fill the apical part then slowly withdrawn while sealer was injected until complete filling of the canal.

In the obturated groups, single ISO size $25 / 6 \%$ master gutta-percha (GP) cone was used. Excess GP was seared off with a hot plugger and radiographs were taken to ensure adequate root filling without voids. All samples were stored at $37^{\circ} \mathrm{C}$ and $100 \%$ humidity for two weeks to ensure complete setting of the sealers.

\section{Fracture resistance testing}

For fracture resistance test, roots were mounted in acrylic resin blocks with the apical $10 \mathrm{~mm}$ of root ends embedded in the resin exposing only $4 \mathrm{~mm}$ of the coronal part of each root. A protractor was used to ensure vertical alignment of the long axis of the roots. The blocks with the vertically aligned roots were then mounted on the lower fixed compartment of the Instron testing machine (Model 3345; Instron, UK). Vertical loading force of $5 \mathrm{kN}$ was applied directly over the canal opening of each root with increasing force at a rate of $1.0 \mathrm{~mm} / \mathrm{min}$, until the root fractured. This point was recorded by the computer monitoring software (BlueHill, Instron) and measured in Newton. Figure (1)

\footnotetext{
* R Core Team (2016). R: A language and environment for statistical computing. R Foundation for Statistical Computing, Vienna, Austria. URL https://www.R-project.org/.
} 


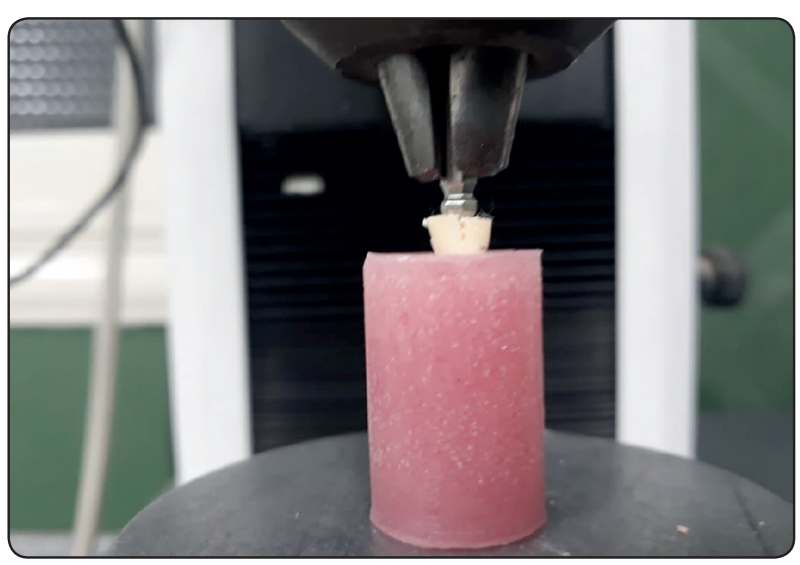

Fig. (1): Fracture resistance test setup.

\section{Statistical analysis}

Fracture resistance was described in terms of mean, median, standard deviation (SD) and range according to each group. Bar graph representing means and standard deviation were used to demonstrate the data.

To test for normality of the data, the Shapiro-Wilk test for normality was applied (Table 1) to choose the proper comparative analysis tests. For normally distributed data, the parametric ANOVA was applied to assess differences regarding fracture resistance. Multiple pairwise comparisons using paired-t test to assess differences in fracture resistance between groups were done. The significance level was verified at $p \leq 0.05$. The results were considered to be statistically significant if $p$-value was less than 0.05 .

Statistical package used for this study was $\mathrm{R}$ statistical package, version 3.3.1 (2016-06-21). Copyright (C) 2016. The R Foundation for Statistical Computing. [Reference: *R Core Team (2016). R: A language and environment for statisticalcomputing. R Foundation for Statistical Computing, Vienna, Austria.URL https://www.R-project.org/.]

\section{RESULTS}

Results were summarized in Table (2) and Figure (2). Unprepared unfilled roots had the highest mean fracture resistance of $519.84( \pm 152.62) \mathrm{N}$, followed by that of AH Plus group with a mean of 453.14 $( \pm 97.47) \mathrm{N}$, then that of the Bioroot RCS group $(393.8 \pm 136.02) \mathrm{N}$, then that of the Endoseal MTA group $(391.47 \pm 121.17) \mathrm{N}$, and prepared unfilled group had the lowest mean fracture resistance of $355.25( \pm 128.45) \mathrm{N}$.

ANOVA test showed that the difference in means between groups was statistically insignificant.

As shown in Table (3), all pair-wise comparisons were statistically insignificant. Hence, there was no statistically significant difference between every two groups with each other.

Table (1): Shapiro-Wilk Test for Normality for fracture resistance regarding each group

\begin{tabular}{|c|c|c|}
\hline \multirow{2}{*}{ Group } & Shapiro-Wilk & \multirow{2}{*}{ Interpretation } \\
\cline { 2 - 3 } & p-value* & \multirow{2}{*}{ Data are Normally distributed } \\
\hline Unprepared-unfilled & 0.2993 & Data are Normally distributed \\
\hline Prepared-unfilled & 0.7827 & Data are Normally distributed \\
\hline AH Plus & 0.9022 & Data are Normally distributed \\
\hline Endoseal MTA & 0.8141 & Data are Normally distributed \\
\hline Bioroot RCS & 0.5429 & \\
\hline
\end{tabular}

*Significance level at p-value $\leq 0.01$. 
TABLE (2): Descriptive analysis of fracture resistance $(\mathrm{N})$ regarding each group and results of the Parametric ANOVA Test for comparing between groups

\begin{tabular}{|c|c|c|c|c|c|c|c|}
\hline \multirow[t]{2}{*}{ Group } & \multirow[t]{2}{*}{ Mean } & \multirow[t]{2}{*}{ SD } & \multirow[t]{2}{*}{ Median } & \multicolumn{2}{|c|}{ Range } & \multicolumn{2}{|c|}{$\begin{array}{c}\text { Parameric ANOVA } \\
\text { test }\end{array}$} \\
\hline & & & & Min & $\operatorname{Max}$ & p-value* & Interpretation \\
\hline Unprepared- unfilled & 519.84 & 152.62 & 507.5 & 344.69 & 728.12 & \multirow{5}{*}{0.1553} & \multirow{5}{*}{$\begin{array}{c}\text { Statistically } \\
\text { insignificant } \\
\text { difference }\end{array}$} \\
\hline Prepared-unfilled & 355.25 & 128.45 & 368.78 & 160.95 & 525.16 & & \\
\hline AH Plus & 453.14 & 97.47 & 436.4 & 292.17 & 613.44 & & \\
\hline Endoseal MTA & 391.47 & 121.17 & 390.37 & 240.56 & 581.22 & & \\
\hline Bioroot RCS & 393.8 & 136.02 & 432.28 & 151.02 & 554.94 & & \\
\hline
\end{tabular}

*Significance level at p-value $\leq 0.05$.

TABLE (3): Multiple pair-wise comparisons using paired t test to assess differences in fracture resistance between groups- results showing p-value*

\begin{tabular}{|c|c|c|c|c|c|}
\hline & $\begin{array}{l}\text { Prepared- } \\
\text { unfilled }\end{array}$ & $\begin{array}{c}\text { Unprepared- } \\
\text { unfilled }\end{array}$ & AH Plus & $\begin{array}{c}\text { Endoseal } \\
\text { MTA }\end{array}$ & $\begin{array}{c}\text { Bioroot } \\
\text { RCS }\end{array}$ \\
\hline Prepared-unfilled & - & & & & \\
\hline Unprepared-Unfilled & 0.07748 & - & & & \\
\hline AH Plus & 0.3475 & 0.0915 & - & & \\
\hline Endoseal MTA & 0.1722 & 0.3732 & 0.627 & - & \\
\hline Bioroot RCS & 0.2109 & 0.627 & 0.3468 & 0.3413 & - \\
\hline
\end{tabular}

*Significance level at p-value $\leq 0.05$.

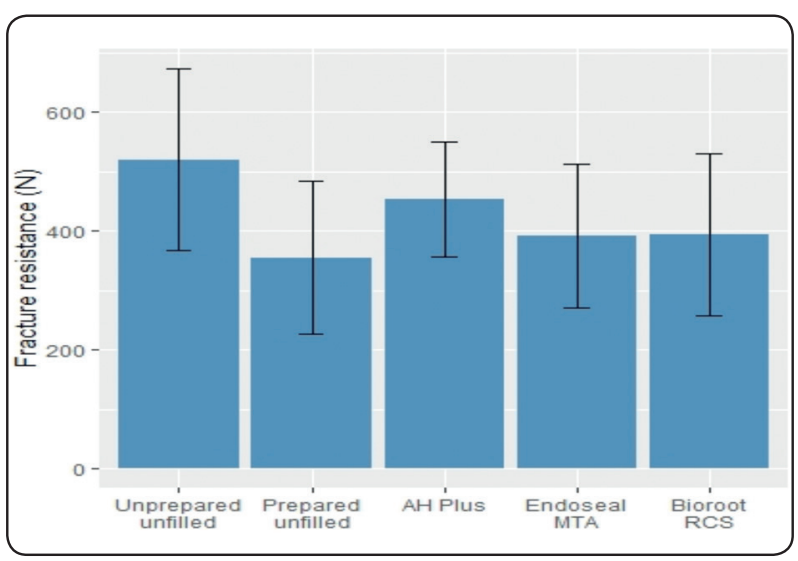

Fig. (2): Comparison between different groups regarding mean fracture resistance- Means and standard deviations

\section{DISCUSSION}

Results of this study showed that there was no statistically significant difference between all groups, so the null hypothesis failed to be rejected. There is a certain believe that root canal preparation weakens the tooth structure exposing it to fracture ${ }^{(30)}$. Hence selection of a material that has a potential to reinforce tooth structure against fracture is of prime concern ${ }^{(31)}$.

It has been reported that preparing root canals with a round cross-section leads to equal distribution of stresses in the root during filling, which decreases the risk of root fracture ${ }^{(32)}$. For this 
reason, rotary files were used in this study for root canal preparation.

All roots were prepared to MPro size 25/6, in order to standardize the apical canal diameter of the enlarged root canals. A standard irrigation regimen, using EDTA and $\mathrm{NaOCl}$ combination, was used to remove the smear layer, to increase bonding of the sealers to the root dentin ${ }^{(33)}$.

In order to exclude both the wedging forces of the spreaders during lateral condensation and the excessive dentin removal required to facilitate the pluggers insertion during vertical condensation, a single-cone obturation technique was used in this study ${ }^{(2,34)}$. Several studies have shown that the single-cone technique would enhance the fracture resistance of teeth better than other obturation techniques ${ }^{(5,35)}$.

Universal testing machine has been used for measurement of fracture resistance of teeth in many studies. In this study, load was vertically applied along the longitudinal axis of the teeth; because in this method, load entirely transfers to the root ${ }^{(36}$, 37). This would result in decreased bending moments and maximum stresses located much more cervical, leading to smaller stresses. This study design is believed to mimic the clinical status, as it simulates the support given to teeth by alveolar bone ${ }^{(6)}$.

The results of the study showed that the fracture resistance of the unprepared-unfilled group was higher than prepared-unfilled group, which proofs that root canal preparation weakens the root. On the other side, the results of all prepared-filled groups were higher than that of the prepared-unfilled group, showing that all tested filling combinations had somehow, reinforced the root against fracture.

The highest mean fracture value was found in the GP and AH Plus group. This might be attributed to the higher adhesion of $\mathrm{AH}$ Plus to root dentin. Sağsen et al. ${ }^{(38)}$, showed that AH Plus sealer increased the fracture resistance of prepared root canals because of its creep capacity and long polymerization period leading to better penetration into the micro-irregularities ${ }^{(39)}$. Besides, the covalent bonds between the epoxy resin and the amino groups of the dentinal collagen might result in a stronger bond of $\mathrm{AH}$ plus to dentin ${ }^{(40,41)}$.

The results of our study came in accordance with Mandava et al. ${ }^{(42)}$, who showed that teeth obturated with AH Plus had a higher fracture resistance than those with the MTA sealer; MTA Fillapex.

Previous studies also showed that AH Plus/GP combination had higher bond strength to dentin than the monoblock system; Resilon/Epiphany, which might be another clue for the ability of this combination to increase fracture resistance of prepared root canals ${ }^{(43,44)}$.

Endoseal MTA is a premixed material supplied in syringes. Its flow is increased by low mean particle size of $1.5 \mu \mathrm{m}{ }^{(45)}$ which is supposed to facilitate its penetration into ramifications and irregularities of root canal system leading to reinforcement of the tooth ${ }^{(46)}$.

Although the results of Endoseal MTA in this study did not significantly differ from AH Plus, yet the lower mean obtained could be attributed to the fact that Endoseal MTA does not actually bond to dentin, rather it deposits hydroxyapatite interfacially, which only increases the frictional resistance of the filling material ${ }^{(45)}$.

BioRoot RCS is a high-purity, tricalcium silicatebased sealer. According to the manufacturer, this sealer is similar in composition to Biodentine (Septodont). Trying to integrate the ideal properties of Biodentine in a root canal sealer, it had been found that there was a mineral infiltration zone when the sealer came in contact with dentin ${ }^{(47)}$. Camilleri ${ }^{(48)}$, had shown the formation of calcium hydroxide in early setting process, which would probably enhance bioactivity and adhesion of BioRoot RCS to the canal walls. The interaction of this sealer with root canal walls because of its bio-mineralization activity, might explain its ability to improve fracture resistance. 


\section{CONCLUSIONS}

Within the limitation of this in vitro study, it can be concluded that Endoseal MTA, and Bioroot $\mathrm{RCS}$, are able to reinforce the tooth against fracture as good as AH Plus.

\section{CONFLICT OF INTEREST}

The authors declare that they have no conflict of interest.

\section{REFERENCES}

1. Helfer AR, Melnick S, Schilder H. Determination of the moisture content of vital and pulpless teeth. Oral Surgery, Oral Medicine, Oral Pathology. 1972 Oct 1;34(4):661-70.

2. Holcomb JQ, Pitts DL, Nicholls JI. Further investigation of spreader loads required to cause vertical root fracture during lateral condensation. Journal of endodontics. 1987 Jun $1 ; 13(6): 277-84$.

3. Sayin TC, Serper A, Cehreli ZC, Otlu HG. The effect of EDTA, EGTA, EDTAC, and tetracycline-HCl with and without subsequent $\mathrm{NaOCl}$ treatment on the microhardness of root canal dentin. Oral Surgery, Oral Medicine, Oral Pathology, Oral Radiology, and Endodontology. 2007 Sep 1;104(3):418-24.

4. Branstetter JV, Von Fraunhofer JA. The physical properties and sealing action of endodontic sealer cements: a review of the literature. Journal of Endodontics. 1982 Jan 1;8(7):312-6.

5. Trope M, Ray Jr HL. Resistance to fracture of endodontically treated roots. Oral surgery, oral medicine, oral pathology. 1992 Jan 1;73(1):99-102.

6. Johnson ME, Stewart GP, Nielsen CJ, Hatton JF. Evaluation of root reinforcement of endodontically treated teeth. Oral Surgery, Oral Medicine, Oral Pathology, Oral Radiology, and Endodontology. 2000 Sep 1;90(3):360-4.

7. TEIXEIRA FB, Teixeira EC, Thompson J, Leinfelder KF, Trope M. Dentinal bonding reaches the root canal system. Journal of Esthetic and Restorative Dentistry. 2004 Nov;16(6):348-54.

8. Teixeira FB, TEIXEIRA EC, THOMPSON JY, TROPE M. Fracture resistance of roots endodontically treated with a new resin filling material. The Journal of the American Dental Association. 2004 May 1;135(5):646-52.
9. Karapinar Kazandag M, Sunay H, Tanalp J, Bayirli G. Fracture resistance of roots using different canal filling systems. International Endodontic Journal. 2009 Aug; 42(8):705-10.

10. Bhat SS, Hegde SK, Rao A, Mohammed AS. Evaluation of resistance of teeth subjected to fracture after endodontic treatment using different root canal sealers: an in vitro study. Journal of Indian Society of Pedodontics and Preventive Dentistry. 2012 Oct 1;30(4):305.

11. Hegde V, Arora S. Fracture resistance of roots obturated with novel hydrophilic obturation systems. Journal of conservative dentistry: JCD. 2015 May;18(3):261.

12. Topçuoğlu HS, Tuncay Ö, Karataş E, Arslan H, Yeter K. In vitro fracture resistance of roots obturated with epoxy resin-based, mineral trioxide aggregate-based, and bioceramic root canal sealers. Journal of endodontics. 2013 Dec 1;39(12):1630-3.

13. Baba SM, Grover SI, Tyagi V. Fracture resistance of teeth obturated with Gutta percha and Resilon: An in vitro study. Journal of conservative dentistry: JCD. 2010 Apr;13(2):61.

14. Jainaen A, Palamara JE, Messer HH. The effect of resinbased sealers on fracture properties of dentine. International endodontic journal. 2009 Feb;42(2):136-43.

15. Kumar P, Kaur NM, Arora S, Dixit S. Evaluation of fracture resistance of roots obturated with resilon and thermoplasticized gutta-percha: An in vitro study. Journal of conservative dentistry: JCD. 2014 Jul;17(4):354.

16. Monteiro J, de Ataide ID, Chalakkal P, Chandra PK. In vitro resistance to fracture of roots obturated with Resilon or gutta-percha. Journal of endodontics. 2011 Jun 1;37(6):828-31.

17. Schäfer E, Zandbiglari T, Schäfer J. Influence of resin-based adhesive root canal fillings on the resistance to fracture of endodontically treated roots: an in vitro preliminary study. Oral Surgery, Oral Medicine, Oral Pathology, Oral Radiology, and Endodontology. 2007 Feb 1;103(2):274-9.

18. Zamin C, Silva-Sousa YT, Souza-Gabriel AE, Messias DF, Sousa-Neto MD. Fracture susceptibility of endodontically treated teeth. Dental Traumatology. 2012 Aug;28(4): 282-6.

19. Zandbiglari T, Davids H, Schäfer E. Influence of instrument taper on the resistance to fracture of endodontically treated roots. Oral Surgery, Oral Medicine, Oral Pathology, Oral Radiology, and Endodontology. 2006 Jan 1;101(1):126-31. 
20. Duarte MA, Marciano MA, Vivan RR, Tanomaru Filho M, Tanomaru JM, Camilleri J. Tricalcium silicate-based cements: properties and modifications. Brazilian oral research. 2018;32.

21. Gandolfi MG, Parrilli AP, Fini M, Prati C, Dummer PM. $3 \mathrm{D}$ micro-CT analysis of the interface voids associated with T hermafil root fillings used with $\mathrm{AH}$ P lus or a flowable MTA sealer. International endodontic journal. 2013 Mar;46(3):253-63.

22. Prati C, Gandolfi MG. Calcium silicate bioactive cements: biological perspectives and clinical applications. Dental materials. 2015 Apr 1;31(4):351-70.

23. Siboni F, Taddei P, Zamparini F, Prati C, Gandolfi MG. Properties of BioRoot RCS, a tricalcium silicate endodontic sealer modified with povidone and polycarboxylate. International endodontic journal. 2017 Dec;50:e120-36.

24. Camps J, Jeanneau C, El Ayachi I, Laurent P, About I. Bioactivity of a calcium silicate-based endodontic cement (BioRoot RCS): Interactions with human periodontal ligament cells in vitro. Journal of endodontics. 2015 Sep 1;41(9):1469-73.

25. Dimitrova-Nakov S, Uzunoglu E, Ardila-Osorio H, Baudry A, Richard G, Kellermann O, Goldberg M. In vitro bioactivity of Bioroot ${ }^{\mathrm{TM}}$ RCS, via A4 mouse pulpal stem cells. Dental Materials. 2015 Nov 1;31(11):1290-7.

26. Prüllage RK, Urban K, Schäfer E, Dammaschke T. Material Properties of a Tricalcium Silicate-containing, a Mineral Trioxide Aggregate-containing, and an Epoxy Resinbased Root Canal Sealer. Journal of endodontics. 2016 Dec $1 ; 42(12): 1784-8$

27. Arias-Moliz MT, Camilleri J. The effect of the final irrigant on the antimicrobial activity of root canal sealers. Journal of dentistry. 2016 Sep 1; 52:30-6.

28. Torabinejad M, Parirokh M.. Mineral trioxide aggregate: a comprehensive literature review-part II: Leakage and biocompatibility investigations. Journal of endodontics 2010; 36:190-202.

29. Guneser MB, Akman M, Kolcu İB, Eldeniz AU. Fracture resistance of roots obturated with a novel calcium silicatebased endodontic sealer (BioRoot RCS). Journal of adhesion science and Technology. 2016 Nov 16;30(22):2420-8.

30. Sagsen B, Er O, Kahraman Y, Akdogan G. Resistance to fracture of roots filled with three different techniques. International endodontic journal. 2007 Jan;40(1):31-5.
31. Stuart CH, Schwartz SA, Beeson TJ. Reinforcement of immature roots with a new resin filling material. Journal of Endodontics. 2006 Apr 1;32(4):350-3.

32. Versluis A, Messer HH, Pintado MR. Changes in compaction stress distributions in roots resulting from canal preparation. International Endodontic Journal. 2006 Dec;39(12):931-9.

33. Kokkas AB, Boutsioukis AC, Vassiliadis LP, Stavrianos CK. The influence of the smear layer on dentinal tubule penetration depth by three different root canal sealers: an in vitro study. Journal of endodontics. 2004 Feb 1;30(2):100-2.

34. Sornkul E, Stannard JG. Strength of roots before and after endodontic treatment and restoration. Journal of Endodontics. 1992 Sep 1;18(9):440-3.

35. Tay FR, Pashley DH. Monoblocks in root canals: a hypothetical or a tangible goal. Journal of endodontics. 2007 Apr 1;33(4):391-8.

36. Lindemuth JS, Hagge MS, Broome JS. Effect of restoration size on fracture resistance of bonded amalgam restorations. Operative dentistry. 2000 May 1;25(3):177-81.

37. De Souza GD, Pereira G, Dias C, Paulillo L. Fracture resistance of premolars with bonded class II amalgams. Operative dentistry. 2002;27(4):349-53.

38. Sağsen B, UeSTUeN Y, PALA K, DEMIRBUĞA S. Resistance to fracture of roots filled with different sealers. Dental materials journal. 2012 Jul 30;31(4):528-32.

39. Nunes VH, Silva RG, Alfredo E, Sousa-Neto MD, SilvaSousa YT. Adhesion of Epiphany and AH Plus sealers to human root dentin treated with different solutions. Brazilian Dental Journal. 2008;19(1):46-50.

40. Fisher MA, Berzins DW, Bahcall JK. An in vitro comparison of bond strength of various obturation materials to root canal dentin using a push-out test design. Journal of endodontics. 2007 Jul 1;33(7):856-8.

41. Neelakantan P, Sharma S, Shemesh H, Wesselink PR. Influence of irrigation sequence on the adhesion of root canal sealers to dentin: a Fourier transform infrared spectroscopy and push-out bond strength analysis. Journal of endodontics. 2015 Jul 1;41(7):1108-11.

42. Mandava J, Chang PC, Roopesh B, Faruddin MG, Anupreeta A, Uma C. Comparative evaluation of fracture resistance of root dentin to resin sealers and a MTA sealer: An in vitro study. Journal of conservative dentistry: JCD. 2014 Jan; 17(1):53. 
43. Ungor M, Onay EO, Orucoglu H. Push-out bond strengths: the Epiphany-Resilon endodontic obturation system compared with different pairings of Epiphany, Resilon, $\mathrm{AH}$ Plus and gutta-percha. International Endodontic Journal. 2006 Aug; 39(8):643-7.

44. Gesi A, Raffaelli O, Goracci C, Pashley DH, Tay FR, Ferrari $\mathrm{M}$. Interfacial strength of Resilon and gutta-percha to intraradicular dentin. Journal of endodontics. 2005 Nov 1;31(11):809-13

45. Yoo YJ, Baek SH, Kum KY, Shon WJ, Woo KM, Lee W, Dynamic intratubular biomineralization following root canal obturation with pozzolan-based mineral trioxide aggregate sealer cement. Scanning. 2016 Jan;38(1):50-6.

46. Silva EJ, Rosa TP, Herrera DR, Jacinto RC, Gomes BP, Zaia AA. Evaluation of cytotoxicity and physicochemical properties of calcium silicate-based endodontic sealer MTA Fillapex. Journal of endodontics. 2013 Feb 1;39(2):274-7.

47. Atmeh AR, Chong EZ, Richard G, Festy F, Watson TF. Dentin-cement interfacial interaction: calcium silicates and polyalkenoates. Journal of dental research. 2012 May;91(5):454-9.

48. Camilleri J. Sealers and warm gutta-percha obturation techniques. Journal of endodontics. 2015 Jan 1;41(1):72-8. 